\title{
A Relationship between Theory of Mind and Pragmatic Language in Adolescents with Mild Intellectual Disabilities
}

\author{
Jeongmin Cheon, Whasoo Kim \\ Department of Speech Pathology, Daegu University, Gyeongsan, Korea
}

Received: April 30, 2020

Revised: June 5, 2020

Accepted: June 8, 2020

Correspondence:

Whasoo Kim, PhD

Department of Speech Pathology,

Daegu University,

201 Daegudae-ro, Jillyang-eup,

Gyeongsan 38453, Korea

Tel: +82-53-850-4324

Fax: +82-53-850-4329

E-mail: whasoolang@hanmail.net

\begin{abstract}
Purpose: The purpose of this study was to investigate the characteristics of pragmatic language ability, which is known to be closely related to the performance level of mind-reading ability of adolescents with mild intellectual disabilities, the theory of mind, and the relationship among them. Methods: A total of 40 (20 adolescents with mild intellectual disabilities aged 19-21 years; 20 children with language age-matched) participated in this study. Mind-reading ability and pragmatic language ability of adolescents with mild intellectual disability and those of children with language age-matched were evaluated and compared. Results: The adolescents with mild intellectual disabilities showed significantly lower performance in mind-reading ability and pragmatic language ability when compared to the control group. Among subtasks of pragmatic language ability, only nonverbal communication was positively correlated with faux pas of mind-reading ability. Conclusion: The present study suggests that mind-reading ability can be related to pragmatic language ability in adolescents with mild intellectual disabilities. We believe that current findings support to understand essential Knowledge required to develop and establish language intervention and communication-related assessment tools that encompass the mind-reading ability of adolescents with mild intellectual disabilities.
\end{abstract}

Key Words: Adolescents with mild intellectual disabilities, Mind-reading ability, Pragmatic language ability, Theory of mind.

\section{INTRODUCTION}

성공적인 의사소통을 위해서는 믿음, 정서, 의도, 바람과 같 은 타인의 마음상태를 이해하는 능력이 필요하다. 타인의 마음 이 행동을 매개하는 일련의 과정에 대해 생각하고, 판단하며, 이해하는 양상들에 대해 최근 이 분야의 학자들은 마음이론 (theory of mind) (Premack \& Woodruff, 1978)이라는 용어로 일컫고 있다. 비슷한 의미에서 마음읽기(Baron-Cohen, 1997), 마음이해(Wellman, 1990) 등의 용어로도 불리고 있다. 마음읽 기는 타인의 생각, 욕구, 감정 등을 정확하게 추론하는 능력과 이러한 추론을 바탕으로 특정 상황에서 타인의 행동을 정확하 게 예측하는 능력의 발달 과정을 보여주며(Song, 2008), 인간 관계를 이해하기 위한 사회성 발달 영역에서 매우 중요한 연구 주제로 주목받고 있다.

이러한 마음읽기능력은 화자의 의도와 청자가 모르는 정보

(c) This is an Open Access article distributed under the terms of the Creative Commons Attribution Non-Commercial License (https://creativecommons.org/licenses/by-nc/4.0) which permits unrestricted non-commercial use, distribution, and reproduction in any medium, provided the original work is properly cited.
가 무엇인지에 대해 생각해 내게 하므로 의사소통에 결정적인 역할을 하게 되며, 역으로 좋은 의사소통기술은 다른 사람들의 마음상태나 믿음에 대한 정보를 해석할 수 있게 한다(Dunn et al., 1991). 근본적으로 아동의 언어와 마음읽기능력은 표상능 력에 의존하여 발달하고 있으며, 특히 언어는 상징적 표상능력 에 효과적인 비계를 제공하여 마음읽기 발달에 중요한 역할을 한다. 뿐만 아니라 믿음, 정서, 의도, 바람과 같은 마음상태도 언어라는 표상적 매개물을 통해서 특정한 내용으로 나타낼 수 있다(Eisenmajer \& Prior, 1991; Jenkins \& Astington, 1996; Kim, 2002).

한편 의사소통에는 화자와 청자, 메시지, 피드백, 상황 맥락 같은 여러 요소들이 포함된다. 성공적인 상호작용은 상황 맥락 속에서 화자와 청자가 메시지와 피드백을 주고받으며 원활한 의사소통을 할 때 이루어지며, 이를 위해서는 적절한 화용언어 능력이 필요하다. 원활한 의사소통을 위해서는 어휘 습득 및 문 법능력의 발달 등과 같은 기본적인 언어능력도 중요하지만 무엇 보다 언어를 적절히 사용하는 측면에서의 화용언어능력이 필수 적으로 요구된다(Kim et al., 2018). 학령전기의 언어 발달이 음 
운 및 구문능력과 같은 언어의 형식적 측면에서 주로 이루어졌 다면, 학령기부터 청소년기까지는 보다 상위 의미인 대화나 담 화능력을 포함한 화용언어능력의 발달로 확장된다(Hoff, 2005; Owens, 2012). 초기 화용언어는 맥락에서의 언어 사용(Prutting \& Kittchner, 1987)이라는 협의의 관점에서 접근하였으나, 최근에는 의사소통기능을 넘어 사회적, 정서적 영역을 포함한 다(Adams, 2005)는 광의적 측면의 개념으로 변화하고 있다. 이 는 사회적 의사소통과 상호작용의 필수요소로서 화용을 보는 넓은 관점에서의 접근(Adams, 2002)과도 유사하다.

사회적 의사소통능력은 화용(pragmatic), 언어 처리(language processing), 사회인지(social cognition), 사회적 상호작 용(social interaction)의 측면으로 나눠지며, 그중 화용은 언어 형태(language form)를 맥락에 맞추어 타인의 의도에 따라 효 율적으로 변화시켜 사용하는 것을 의미한다(Adams, 2005). 그 러나 타인의 의도, 정서, 믿음, 바람과 관련한 마음읽기능력의 발달에 결함을 보이는 아동의 경우, 화용언어능력에도 어려움 이 있을 것으로 추측할 수 있다.

전형적 발달을 보이는 아동의 경우 초기 발달단계부터 화용 언어 영역에서 의사소통기능이 나타나며, 이러한 의사소통기능 은 점차 언어를 습득하고 사회인지가 발달함에 따라 더욱 구체 화된다(Philofsky et al., 2007). 그러나 지적장애 아동은 선천 적으로 지적능력의 결함을 가지고 태어나 판단 및 통찰, 언어능 력 등의 결핍이 수반된다(Cheon \& Kim, 2017). 지적장애 아동 과 언어 발달 수준이 동일한 일반 아동을 비교했을 때 인지 발 달이나 언어의 구문 및 의미적 구조에서 어려움을 나타내며, 가장 두드러지는 결함은 언어의 사용, 즉 사회적 의사소통능력 의 느린 발달이다(Kim, 1991; Kim \& An, 2017). 화용언어능력 의 손상이 사회적 의사소통 및 상호작용에도 부정적인 영향을 미치게 되는 것은 자명한 사실이다. 지적장애 아동에게도 마찬 가지로 또래와 형성하는 대인관계와 상호작용은 사회적 기술 의 핵심적인 부분이며, 정서 및 사회성 발달에서부터 삶의 질에 이르기까지 매우 큰 영향을 미치게 된다. 이러한 사회적 상호작 용 역량은 청소년기에 더욱 크게 요구받게 되는데, 이는 청소년 기가 되면 학교에서 생활하는 시간이 훨씬 길어지고 학교 내에 서 차지하는 언어 활동의 비중과 역할도 더욱 커지기 때문이다. 지적장애 청소년들에게 나타나는 상호작용의 부재는 결국 학 교에서의 고립을 낳는다.

지적장애 청소년이 질 높은 삶을 영위하기 위해서는 대인관계 를 통한 상호작용이 무엇보다 중요하나 장애의 특성으로 대인관 계가 원만치 못한 제한성의 문제가 뒤따른다(Cheon \& Kim, 2017). 특히 원만한 사회적 의사소통능력에 필수적으로 동반되 는 마음상태라는 요소는 화용언어와 밀접한 관련이 있으며, 외 현적이지 않을 뿐만 아니라 표상이라는 특성을 지니고 있어서
행동과 마음 관련하여 이해하는 것이 지적장애 청소년에게는 더욱 어렵게 느껴질 수 있다. 마음읽기능력은 연령이 증가할수 록 마음상태를 알려주는 분명한 단서가 없는 상황에서도 상대 방의 마음상태를 읽을 수 있는 등의 좀 더 고차원적인 능력이 발달할 것으로 예측할 수 있다. 이러한 능력으로 고려해 볼 수 있는 것은 그간 마음이론 연구자들에게서 공통적으로 연구된 몇 가지를 예로 들 수 있다. 먼저, 다른 사람의 마음상태에 대 해 또 다른 사람이 이해하는 것을 의미하는 이차순위 마음읽 기는 특정 상황을 다른 사람이 어떻게 마음속에 표상하는지 아는 것을 의미한다(Perner \& Wimmer, 1985). 이밖에도 여러 가지 의미로 해석될 수 있는 애매한 행동의 다양한 의미를 파 악하는 능력(Bosacki \& Astington, 1999; O’Connor \& Hirsch, 1999), 뜻이 숨겨진 말을 표면적인 뜻 그대로 이해하지 않고 내 포된 의미를 알아내는 능력(Happé, 1993), 그리고 화자가 청자 에 대한 특정한 사실을 알지 못하여 의도하지 않았음에도 불 구하고 실수로 상대방의 기분을 나쁘게 하는 말을 할 수 있음 을 아는 능력(Baron-Cohen et al., 1999)이 있다.

이러한 마음읽기능력은 학급 상황에서 또래나 교사의 마음 을 잘 읽고 적절하게 반응함으로써 좋은 관계를 형성하고 학교 생활에 좀 더 쉽게 적응할 수 있기 때문에 학급에서의 상호작 용 요구가 더욱 커지는 청소년기 학생에게 있어서 특히 더 중요 하다. 또한 이는 향후 청소년기 학생이 겪게 될 또 다른 사회생 활의 적응에도 긍정적으로 작용할 것임이 분명하다. 이러한 맥 락에서 지적장애 청소년의 마음읽기능력 발달과 화용언어능력 의 특성을 살펴보는 것은 이들이 친밀하고 안정적인 또래관계 를 맺고 주변 환경에 잘 적응하도록 돕는 데 도움이 되는 방법 을 모색하는 것으로, 지적장애 청소년이 청소년기뿐만 아니라 이후의 사회적, 직업적 적응을 원만하게 하는 데에도 큰 영향 을 미치는 일이라 할 수 있겠다.

이러한 관점에서 본 연구는 경도지적장애 청소년과 일반 아 동을 대상으로 마음읽기능력과 화용언어능력의 특성을 살펴보 고, 두 변인 간 연관성을 탐색해 보고자 한다. 연구 문제는 다음 과 같다.

1) 경도지적장애 청소년 집단과 일반 아동 집단 간 마음읽기 능력 수행에 차이가 있는가?

2) 두 집단 간 화용언어능력 수행에 차이가 있는가?

3) 두 집단의 마음읽기능력과 화용언어능력 간 연관성이 있 는가?

(1) 마음읽기능력과 화용언어능력의 하위과제 간 상관관계가 있는가?

(2) 화용언어능력에 대하여 마음읽기능력의 하위과제에 따 른 인과관계가 있는가? 


\section{MATERIALS AND METHODS}

\section{연구 대상}

본 연구는 대구·경북지역에 거주하고 생활연령이 만 19 21세, 언어연령이 만 10 12세인 경도지적장애 청소년 20명, 그리고 이 들 청소년과 언어연령을 일치시킨 일반 아동 20 명, 총 40 명을 대상으로 실시하였다.

경도지적장애 청소년 집단은 다음의 세부 기준에 따라 선정 하였다. 1) 한국 웩슬러 성인지능검사 4판(Korean Wechsler adult intelligence scale-IV)을 실시한 결과, Full Scale Intelligence Quotient (FSIQ)가 50 이상 70 이하에 속하고, 2) $\mathrm{Di}^{-}$ agnostic and statistical manual of mental disorders, fifth edition (American Psychiatric Association, 2013)의 지적장애 심각도 기준에서 경도에 해당하며, 3) 수용·표현 어휘력검사 (Receptive \& Expressive Vocabulary Test, REVT) 결과 수용 및 표현 등가연령이 만 $10 \sim 12$ 세에 해당하면서, 4) 지적장애를 제외한 자폐스펙트럼장애나 시각장애, 청각장애, 뇌병변장애 등 본 연구의 검사 수행에 제한을 줄 수 있는 기타 장애를 동반 하지 않은 청소년으로 선정하였다.

일반 아동 집단은 1) 한국 웩슬러 아동지능검사 5판(Korean Wechsler intelligence scale for children-V)을 실시한 결과 FSIQ가 90 이상에 속하고, 2) 수용·표현 어휘력검사(REVT) 결 과 수용 및 표현 등가연령이 만 10 12세에 해당하면서, 3) 부모 나 교사 보고로 인지, 신체, 언어 발달이 정상이며, 시각과 청각 기타 신경학적 문제가 없는 것으로 보고된 아동으로 선정하였다.

집단에 대한 통제가 잘 이루어졌는지 확인하기 위하여 독립표 본 $t$-검정을 실시하였다. 그 결과 생활연령 및 지능지수를 제외 한 수용 및 표현 어휘력에서 집단 간에 유의미한 차이를 보이지 않았다. 두 집단의 인구통계학적 특성은 Table 1에 제시하였다.

\section{연구 도구}

마음읽기능력검사

본 검사는 총 네 가지의 하위과제로 구성되어 있고, 각 하위
과제마다 마음읽기능력을 확인할 수 있는 다양한 이야기 자료 들이 포함되어 있다. 검사를 실시하기에 앞서 Choi \& Ghim (2008)의 연구에서 사용된 마음읽기 과제를 경도지적장애 청 소년의 언어 수준에 맞추어 수정·보완하는 과정을 거쳐 사용 하였다. 마음읽기능력검사에 대한 전반적인 구성 및 하위과제 별 문항 예시는 Appendix 1, 2에 제시하였다.

화용언어능력검사(Children's Pragmatic Language Checklist)

본 검사는 Oh et al.(2012)이 개발한 주 양육자나 교사, 언어 치료사 등 아동을 잘 아는 성인이 아동의 일상생활 내 화용언 어능력을 묻는 문항에 대하여 Likert 4점 척도 $(3$ = 항상 그렇 다, 2 = 그렇다, 1 = 그렇지 않다, 0 = 전혀 그렇지 않다)로 대답 하게끔 되어 있는 체크리스트이다. 담화 관리, 상황에 따른 조 절, 의사소통 의도, 비언어적 의사소통의 네 가지 하위과제로 이루어져 있으며, 총 47개 문항으로 구성되어 있다. Children's Pragmatic Language Checklist (CPLC)는 예비연구를 통해 내적 타당도와 신뢰도가 입증되었으며, 현재 표준화 과정 중에 있는 도구로 비교적 짧은 시간 내에 아동의 일상생활에서의 화 용언어능력 수준을 알아볼 수 있다는 장점이 있다. 경도지적장 애 청소년과 일반 아동 모두 해당 연구 참여자의 화용언어능력 에 대해 가장 잘 이해하고 있는 보호자나 부모가 직접 체크하도 록 하였다. 경도지적장애 청소년의 경우 REVT를 통해 언어연 령을 만 10 12세로 통제하였기 때문에 본 연구에서는 초등학 교 고학년 아동의 언어능력 수준을 가지고 있다는 전제하에 보호자 및 생활지도교사에게 본 체크리스트 작성을 요청하였 다. $\mathrm{CPLC}$ 의 전반적인 구성은 Appendix 3에 제시하였다.

\section{연구 절차}

마음읽기능력검사는 17 개의 마음읽기능력 과제를 그림 자료 와 함께 제시하였다. 각 과제마다 4 6컷에 해당하는 그림 자료 를 파워포인트에서 슬라이드 쇼로 만들어 애니메이션처럼 보이 도록 구성하였다. 독립된 조용한 공간에서 연구 참여자와 연구 자가 서로 마주보고 앉은 상태로 Macbook Air 2019(Apple, Cupertino, CA, USA)과 iPad Pro 11 inch (3rd generation,

Table 1. Comparison of characteristics between adolescents with mild intellectual disability and children with typical development

\begin{tabular}{|c|c|c|c|c|c|}
\hline \multirow{2}{*}{ Characteristic } & \multicolumn{2}{|c|}{$\operatorname{MID}(n=20)$} & \multicolumn{2}{|c|}{$\mathrm{TD}(\mathrm{n}=20)$} & \multirow{2}{*}{$t$} \\
\hline & Mean & SD & Mean & $\mathrm{SD}$ & \\
\hline Age (mo) & 245.85 & 11.25 & 124.30 & 5.74 & $43.026^{* * *}$ \\
\hline FSIQ $^{\dagger}$ & 61.40 & 3.87 & 108.50 & 8.56 & $-22.41^{* * *}$ \\
\hline Receptive vocabulary $^{\ddagger}$ & 140.75 & 9.34 & 137.35 & 7.44 & 1.273 \\
\hline Expressive vocabulary $^{\ddagger}$ & 137.25 & 8.98 & 139.90 & 9.59 & -0.902 \\
\hline
\end{tabular}

${ }^{* * *} p<0.001$. ${ }^{\dagger}$ Korean Wechsler adult intelligence scale-IV (Hwang et al., 2012), Korean Wechsler intelligence scale for children-V (Kwak \& Jang, 2019), ${ }^{*}$ Receptive \& Expressive Vocabulary Test (Kim et al., 2009). MID: adolescent with mild intellectual disability, TD: children with typical development, SD: standard deviation, FSIQ: Full Scale Intelligence Quotient 
Apple)를 사용하여 1:1 방식으로 검사를 진행하였다. 연구자는 검사에 앞서 연구 참여자에게 다음과 같은 지시문을 들려주었 다. "지금부터 선생님이 $\bigcirc \bigcirc($ 이)에게 재미있는 이야기를 들려 줄 거예요. 이야기에는 몇 가지 그림이 같이 나오니까 그림도 잘 봐야 해요. 그리고 선생님이 중간중간에 질문을 할 건데, 질 문들은 따로 정답이 있는 것이 아니에요. $\bigcirc \bigcirc$ (이)가 생각하는 대로 편하게 대답하면 돼요. 이야기를 집중해서 잘 듣고, 질문 에 대답해 주세요." 이후 연구 참여자들은 과제의 이야기와 질 문을 들으며, Macbook Air 2019에 연결된 iPad Pro 11 inch로 각 과제에 대한 그림 자료를 보았다. 17 개의 마음읽기능력 과제 들은 무작위 순서로 제시되었다. 중간에 대상자가 지루해하거 나 힘들어하는 기색을 보이는 경우에는 5 분씩 쉬어가며 검사 를 이어갔다. 본 검사는 한 회기에 실시하는 것을 원칙으로 하 였으나 연구 참여자가 한 회기 내에 검사를 끝마치기에 어려움 이 있을 것으로 판단되는 경우, 두 회기로 나누어 진행하였으며 두 검사의 실시 간격은 최대 일주일을 넘기지 않도록 하였다. 연구 참여자들의 대답은 Macbook Air 2019에 직접 전사하여 저장하였으며, 검사가 끝난 후 내용을 분석하였다.

$\mathrm{CPLC}$ 는 연구 참여에 동의한 경도지적장애 청소년 및 일반 아동의 보호자 및 부모가 직접 작성하도록 하였다. 본 체크리 스트는 체크리스트를 작성하는 대상자의 직접적인 관찰과 판 단에 근거하여 작성하게 되어 있으므로 연구 참여자와 적어도 주 4일 이상 함께 생활하며, 연구 참여자의 의사소통적 특성을 상세히 알고 있는 보호자나 부모에게 실시하도록 하였다. 연구 자는 체크리스트를 작성하는 보호자 및 부모에게 문항을 주의 깊게 읽고, 문항 옆에 제시되어 있는 Likert 4점 척도 $(3=$ 항상 그렇다, 2 = 그렇다, 1 = 그렇지 않다, $0=$ 전혀 그렇지 않다) 중 하나를 선택하도록 설명하였다. 또한 보호자 및 부모가 47 개의 모든 문항을 빠트리지 않고 체크하도록 안내하였다.

\section{내용 타당도}

본 연구에서 사용된 마음읽기능력검사 및 CPLC에 대해 임 상 경력 5년 이상의 언어발달장애 전공 박사과정 수료생 4 명, 임 상 경력 10 년 이상의 언어병리학박사 1 명으로부터 실험 도구의 적합성에 대한 내용 타당도를 검증하였다. Likert 5 점 척도 $(5=$ 매우 적합하다, $4=$ 적합하다, $3=$ 보통이다, $2=$ 적합하지 않다, $1=$ 매우 적합하지 않다)를 적용한 결과 마음읽기능력의 네 가 지 하위과제에 대해 평균 4.72점, CPLC의 네 가지 하위과제에 대해 평균 4.93점을 획득하였다.

\section{신뢰도}

본 연구에 참여한 대상자의 마음읽기능력검사 과정을 비디 오카메라로 녹화하였고, 녹화 자료 중 집단별로 무작위 $20 \%$ 를
선정하여 경도지적장애 청소년 4명, 일반아동 4명의 반응에 대 해 본 연구자와 1 급 언어치료사 자격증을 소지한 임상 경력 5 년 이상의 박사과정 수료생 1 명이 각각 독립적으로 평가한 후 평가자 간 신뢰도를 산출하였다. 연구자는 평가에 참여한 제2 평가자에게 사전에 연구의 목적과 평가 방법에 대해 설명하였 으며, 채점 기준에 따른 채점 방법을 정확히 숙지하고 연습한 후 평가에 참여할 수 있도록 하였다. 이에 따른 마음읽기능력검 사 결과 $95.3 \%$ 일치의 평가자 간 신뢰도를 나타내었다.

$\mathrm{CPLC}$ 에 대하여 검사-재검사 신뢰도와 평가자 간 신뢰도를 측정하였다. 검사-재검사 신뢰도는 해당 대상자의 화용언어능 력에 대해 첫 분석을 실시한 날로부터 최소 1 개월이 지난 이후 집단별로 무작위 $20 \%$ 를 선정하여 경도지적장애 청소년 4명, 일반 아동 4명의 보호자나 부모가 다시 체크리스트를 작성하 였다. Pearson 적률상관계수를 산출하여 신뢰도를 측정한 결 과 0.89 로 높은 신뢰도를 보였다. 평가자 간 신뢰도는 경도지적 장애 청소년의 경우 해당 대상자의 생활 전반적인 부분을 담당 하고 언어적 특성에 대해 깊이 이해하고 있는 생활지도교사 4 명이 분석에 참여하였으며, 일반 아동의 경우 학급 담임교사 4 명이 분석에 참여하였다. 그 결과 Pearson 적률상관계수 0.83 으로 높은 신뢰도를 보였다.

\section{자료 분석}

본 연구에서 수집된 자료는 SPSS/Win 25.0(IBM Corp., Armonk, NY, USA)을 사용하여 분석하였다. 두 집단에서 하 위과제에 따른 마음읽기능력과 화용언어능력에 수행 차이가 나타나는지 알아보기 위해 집단(2) $\times$ 하위과제(4)의 반복측정 분산분석(repeated measures analysis of variance)을 실시하 였으며, 각 집단의 마음읽기능력과 화용언어능력의 하위과제 및 총점 간 상관관계가 나타나는지 알아보기 위해 Pearson 적 률상관계수(Pearson product-moment correlation coefficient) 를 산출하였다.

\section{RESULTS}

\section{두 집단 간 마음읽기능력 수행 차이 비교}

두 집단의 하위과제(이차순위 틀린 믿음, 모호한 상황에서의 마음읽기, 숨은 의미 파악, 헛디딤 말)에 따른 마음읽기능력 수 행력에 대한 백분율의 기술통계는 Table 2에 제시하였다.

하위과제에 따른 마음읽기능력의 수행력이 집단과 과제에 따른 차이가 있는지, 집단과 하위과제의 상호작용 효과가 나타 나는지에 대한 통계적 유의성을 검정한 반복측정 분산분석의 결과는 Table 3에 제시하였다.

분석 결과에 따르면 두 집단 간의 하위과제에 따른 마음읽기 
능력 수행에서 통계적으로 유의미한 차이가 있는 것으로 나타 났다 $[\mathrm{F}(1,38)=19.184, p<0.001]$. 또한 집단 내에서 네 가지 하위과제에 따른 주 효과가 있었으며 $[\mathrm{F}(3,114)=21.436, p<$ 0.001], 집단과 하위과제 간의 상호작용 효과도 통계적으로 유 의미한 것으로 나타났다 $[\mathrm{F}(3,114)=0.732, p<0.05]$.

구체적으로 어떠한 과제 간에 통계적으로 유의미한 차이가 있는지를 알아보기 위하여 독립표본 $t$-검정을 통한 사후검정 을 실시하였으며, 그 결과는 Table 4와 Figure 1에 제시하였다.

Table 4에 따르면 경도지적장애 청소년과 언어연령 일치 아 동 간 이차순위 틀린 믿음 $[t(38)=-2.250, p<0.05]$, 모호한 상황에서의 마음읽기 $[t(38)=-3.095, p<0.01]$, 숨은 의미 파 악 $[t(38)=-2.295, p<0.05]$, 헛디딤 말[t(38) $=-2.789, p<$ $0.01]$ 모두에서 유의미한 발달 차이가 나타났다. 그중에서 헛디 딤 말은 경도지적장애 청소년의 평균점수가 43.70점, 언어연령 일치 아동의 평균점수가 62.05점으로 두 집단 간 가장 큰 수행 력 차이를 보이는 하위과제였다.

Figure 1에서 경도지적장애 청소년과 언어연령 일치 아동 모 두 이차순위 틀린 믿음 > 숨은 의미 파악 > 헛디딤 말 > 모 호한 상황에서의 마음읽기 순의 수행력을 나타내었다.

\section{두 집단 간 화용언어능력 수행 차이 비교}

두 집단의 하위과제(담화 관리, 상황에 따른 조절, 의사소통 의도, 비언어적 의사소통)에 따른 마음읽기능력 수행력에 대한 백분율의 기술통계는 Table 5 에 제시하였다.

하위과제에 따른 화용언어능력의 수행력이 집단과 과제에 따른 차이가 있는지, 집단과 하위과제의 상호작용 효과가 나타 나는지에 대한 통계적 유의성을 검정한 반복측정 분산분석의 결과는 Table 6에 제시하였다.

분석 결과에 따르면 두 집단 간의 하위과제에 따른 화용언어 능력 수행에서 통계적으로 유의미한 차이가 있는 것으로 나타 났다[F(1, 38) $=25.656, p<0.001]$. 또한 집단 내에서 네 가지 하위과제에 따른 주 효과가 있었으며 $[\mathrm{F}(3,114)=3.630, p<$ 0.01], 집단과 하위과제 간의 상호작용 효과도 통계적으로 유의 미한 것으로 나타났다[F(3,114) $=1.739, p<0.05]$.

구체적으로 어떠한 과제 간에 통계적으로 유의미한 차이가 있는지를 알아보기 위하여 독립표본 $t$-검정을 통한 사후검정 을 실시하였으며, 그 결과는 Table 7과 Figure 2에 제시하였다.

Table 7에 따르면 화용언어능력 하위과제에 따른 수행력은 담화 관리와 상황에 따른 조절 간 $(p<0.01)$, 담화 관리와 의사 소통 의도 간 $(p<0.01)$, 담화 관리와 비언어적 의사소통 간 $(p<$ $0.05)$, 상황에 따른 조절과 비언어적 의사소통 간 $(p<0.01)$, 의

Table 2. Comparison of descriptive statistics on the performance of mild-reading ability according to subtasks between groups

\begin{tabular}{lcccc}
\hline Group & Second-order false belief & Mind-reading in ambiguous situation & Apprehension of hidden meaning & Faux pas \\
\hline MID & $67.50(15.39)$ & $41.00(12.83)$ & $62.05(13.29)$ & $43.70(18.97)$ \\
TD & $77.55(12.73)$ & $56.95(19.14)$ & $72.30(14.91)$ & $62.05(22.49)$ \\
\hline
\end{tabular}

MID: adolescent with mild intellectual disability, TD: children with typical development

Table 3. Repeated measures analysis of variance on the performance of mind-reading ability according to groups and subtasks

\begin{tabular}{|c|c|c|c|c|c|}
\hline Source & SS & df & MS & $\mathrm{F}$ & $p$-value \\
\hline \multicolumn{6}{|l|}{ Between groups } \\
\hline Group & 7452.900 & 1 & $7,452.900$ & 19.184 & $<0.001$ \\
\hline Error & $14,763.075$ & 38 & 388.502 & & \\
\hline \multicolumn{6}{|l|}{ Within groups } \\
\hline Subtasks & $15,202.875$ & 3 & $5,067.625$ & 21.436 & $<0.001$ \\
\hline Subtasks $\times$ groups & 519.000 & 3 & 173.000 & 0.732 & $<0.05$ \\
\hline Error (subtasks) & $26,950.125$ & 114 & 236.405 & & \\
\hline
\end{tabular}

SS: sum of squares, MS: mean square

Table 4. Post-hoc on the performance of mind-reading ability according to subtasks between groups

\begin{tabular}{|c|c|c|c|c|c|}
\hline \multirow{2}{*}{ Subtasks } & \multicolumn{2}{|c|}{$\operatorname{MID}(\mathrm{n}=20)$} & \multicolumn{2}{|c|}{$\mathrm{TD}(\mathrm{n}=20)$} & \multirow{2}{*}{$t$} \\
\hline & Mean & SD & Mean & $\mathrm{SD}$ & \\
\hline Second-order false belief & 67.50 & 15.39 & 77.55 & 12.73 & $-2.250^{*}$ \\
\hline Mind-reading in ambiguous situation & 41.00 & 12.83 & 56.95 & 19.14 & $-3.095^{* *}$ \\
\hline Apprehension of hidden meaning & 62.05 & 13.29 & 72.30 & 14.91 & $-2.295^{*}$ \\
\hline Faux pas & 43.70 & 18.97 & 62.05 & 22.49 & $-2.789^{* *}$ \\
\hline
\end{tabular}

${ }^{*} p<0.05,{ }^{* *} p<0.01$. MID: adolescent with mild intellectual disability, TD: children with typical development, SD: standard deviation 
Figure 1. Comparison of performance among groups by mind-reading ability subtasks. ${ }^{*} p<0.05,{ }^{* *} p<0.01$. MID: adolescent with mild intellectual disability, TD: children with typical development.

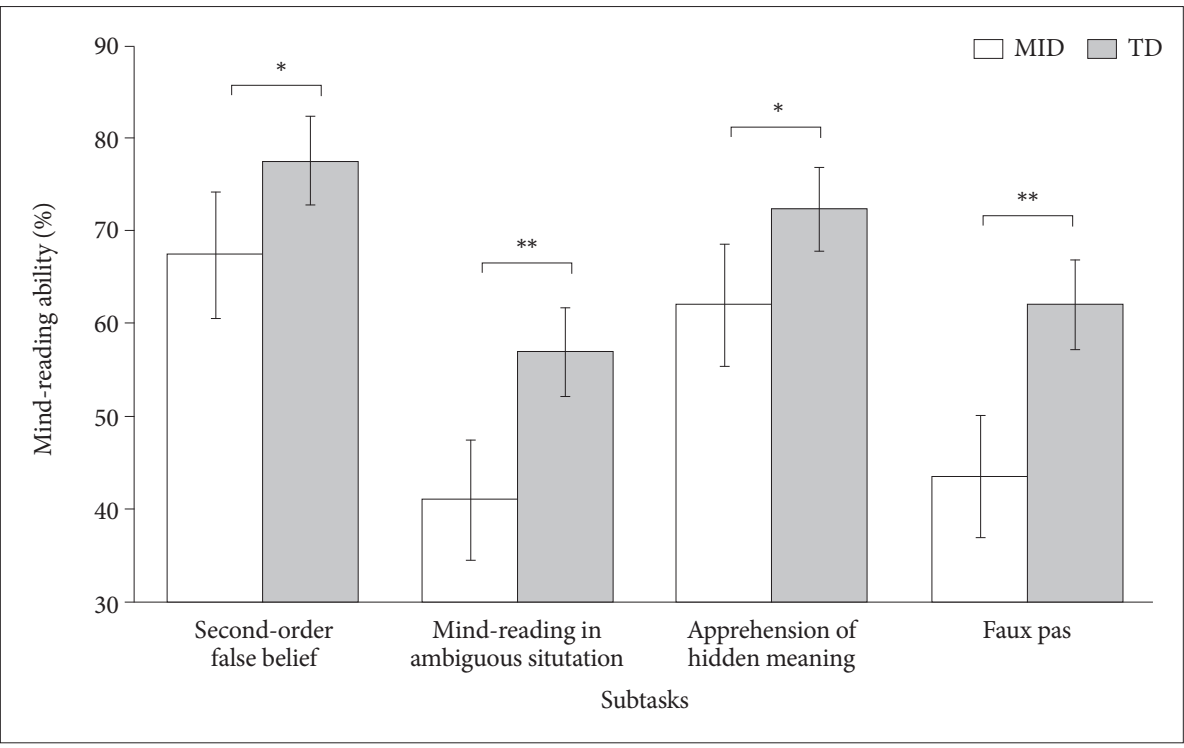

Table 5. Comparison of descriptive statistics on the performance of pragmatic language ability according to subtasks between groups

\begin{tabular}{ccccc}
\hline Group & Discourse management & Contextual variation & Communication intention & Nonverbal communication \\
\hline MID & $72.75(7.96)$ & $69.30(11.29)$ & $76.50(9.02)$ & $69.65(10.69)$ \\
TD & $81.10(6.53)$ & $82.40(7.63)$ & $83.05(5.76)$ & $80.45(7.36)$ \\
\hline
\end{tabular}

MID: adolescent with mild intellectual disability, TD: children with typical development

Table 6. Repeated measures analysis of variance on the performance of pragmatic language ability according to groups and subtasks

\begin{tabular}{lrrrrr}
\hline \multicolumn{1}{c}{ Source } & \multicolumn{1}{c}{ SS } & df & MS & F & $p$-value \\
\hline Between groups & & & & 25.656 & $<0.001$ \\
$\quad$ Group & $3,763.600$ & 1 & $3,763.600$ & 146.692 & \\
$\quad$ Error & $5,574.300$ & 38 & & 3.630 & $<0.01$ \\
Within groups & & & 170.550 & 1.739 & $<0.05$ \\
$\quad$ Subtasks & 511.650 & 3 & 81.717 & & \\
Subtasks $\times$ groups & 245.150 & 3 & 46.980 & & \\
$\quad$ Error (subtasks) & $5,355.700$ & 114 &
\end{tabular}

SS: sum of squares, MS: mean square

사소통 의도와 비언어적 의사소통 간 $(p<0.01)$ 유의미한 차이 가 있는 것으로 나타났다.

Figure 2에서 경도지적장애 청소년은 의사소통 의도 > 담 화관리 > 비언어적 의사소통 > 상황에 따른 조절 순의 수행 력을, 언어연령 일치 아동은 의사소통 의도 > 상황에 따른 조 절 > 담화 관리 > 비언어적 의사소통 순의 수행력을 나타내 두 집단 모두 의사소통 의도에서의 수행력이 가장 높았다.

\section{두 집단의 마음읽기능력과 화용언어능력 간 연관성}

마음읽기능력과 화용언어능력의 하위과제 간 상관관계에 대 해 집단별로 살펴본 결과를 Table 8과 9에 각각 제시하였다.

경도지적장애 청소년 집단에서는 이차순위 틀린 믿음과 모 호한 상황에서의 마음읽기 간( $\mathrm{r}=0.601, p<0.01)$, 모호한 상
황에서의 마음읽기와 숨은 의미 파악 간 $(\mathrm{r}=0.608, p<0.01)$, 숨은 의미 파악과 헛디딤 말 간 $(\mathrm{r}=0.456, p<0.05)$, 담화 관 리와 상황에 따른 조절 간 $(\mathrm{r}=0.819, p<0.01)$, 헛디딤 말과 비 언어적 의사소통 간 $(\mathrm{r}=0.455, p<0.05)$ 에 유의미한 정적 상 관을 나타내었다.

일반 아동 집단에서는 담화 관리와 상황에 따른 조절 간 $(\mathrm{r}=$ $0.647, p<0.01$ )에서만 유의미한 정적 상관이 나타났다.

\section{DISCUSSIONS}

본 연구의 목적은 경도지적장애 청소년과 일반 아동을 대상 으로 마음읽기능력과 화용언어능력의 특성을 살펴보고, 두 변 인 간 연관성을 탐색하는 데 있다. 
Table 7. Post-hoc on the performance of pragmatic language ability according to subtasks between groups

\begin{tabular}{|c|c|c|c|c|c|}
\hline \multirow{2}{*}{ Subtasks } & \multicolumn{2}{|c|}{$\operatorname{MID}(n=20)$} & \multicolumn{2}{|c|}{$\mathrm{TD}(\mathrm{n}=20)$} & \multirow{2}{*}{$t$} \\
\hline & Mean & $\mathrm{SD}$ & Mean & $\mathrm{SD}$ & \\
\hline Discourse management & 72.75 & 7.96 & 81.10 & 6.53 & $-3.624^{* *}$ \\
\hline Contextual variation & 69.30 & 11.29 & 82.40 & 7.63 & $-4.299^{* * *}$ \\
\hline Communication intention & 76.50 & 9.02 & 83.05 & 5.76 & $-2.736^{* *}$ \\
\hline Nonverbal communication & 69.65 & 10.69 & 80.45 & 7.36 & $-3.718^{* *}$ \\
\hline
\end{tabular}

${ }^{* *} p<0.01,{ }^{* * *} p<0.001$. MID: adolescent with mild intellectual disability, TD: children with typical development, SD: standard deviation

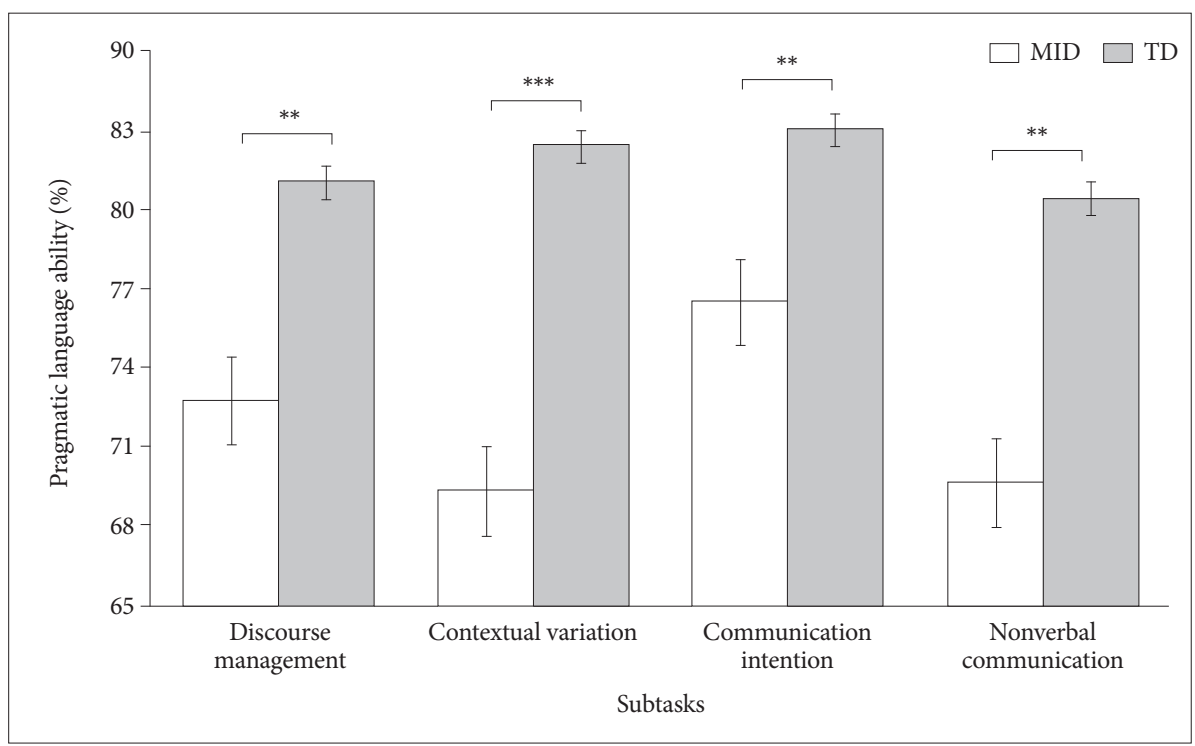

Figure 2. Comparison of performance among groups by pragmatic language ability subtasks. ${ }^{* *} p<0.01,{ }^{* * *} p<0.001$. MID: adolescent with mild intellectual disability, TD: children with typical development.

Table 8. Correlation coefficient between subtasks of mind-reading ability and pragmatic language ability of adolescents with mild intellectual disabilities

\begin{tabular}{llllllll}
\hline Category & \multicolumn{1}{c}{ SF } & MA & AH & FP & DM & CV & CI \\
\hline SF & 1 & & & & & & \\
MA & $0.601^{* *}$ & 1 & & & & & \\
AH & 0.359 & $0.608^{* *}$ & 1 & & & & \\
FP & 0.063 & 0.419 & $0.456^{*}$ & 1 & & & \\
DM & 0.072 & 0.439 & 0.418 & 0.435 & 1 & & 1 \\
CV & -0.104 & 0.369 & 0.355 & 0.284 & $0.819^{* *}$ & 1 & 0.334 \\
CI & 0.041 & 0.171 & 0.048 & -0.163 & 0.372 & 0.217 & 1 \\
NC & 0.054 & 0.386 & 0.233 & $0.455^{*}$ & 0.400 & 0.271 & \\
\hline
\end{tabular}

${ }^{*} p<0.05,{ }^{* *} p<0.01$. SF: second-order false belief, MA: mind-reading in ambiguous situation, AH: apprehension of hidden meaning, FP: faux pas, DM: discourse management, $\mathrm{CV}$ : contextual variation, $\mathrm{CI}$ : communication intention, NC: nonverbal communication

먼저 경도지적장애 청소년 집단과 일반 아동 집단 간 마음읽 기능력에서 수행 차이가 나타나는지 확인하기 위해 마음읽기 능력 검사를 실시한 결과, 모든 하위과제에서 경도지적장애 청 소년이 일반 아동보다 유의미하게 낮은 발달 수준을 보이는 것 으로 나타났다. 일반적으로 이차순위 틀린 믿음은 표상적 이해 를 획득한 7세 이후 발달하며, 11세 이후 더이상 발달적 변화를 보이지 않는다(Yi et al., 2007). 그러나 이러한 주장은 지적장애 청소년에게는 다소 적용되기 어려운 발달 지표일 수 있다. Jeon(1996)에 따르면 지적장애 아동의 화용언어능력은 생활연
령, 사회연령, 정신연령의 세 가지 변인 중 사회연령과 깊은 관계 가 있다고 하였다. 본 연구에서 밝힌 마음이론과 화용언어능력 간 밀접한 상관관계가 있다는 결과를 바탕으로 보았을 때, 마 음이론 역시 생활연령 및 정신연령이 아닌 사회연령으로 접근 하여 논의하는 것이 타당할 것으로 보인다. 자폐스펙트럼장애 아동을 대상으로 틀린 믿음 과제를 실시한 연구(Baron-Cohen et al., 1985)에 의하면 자폐스펙트럼장애 아동은 장애가 없는 4,5 세의 일반 아동뿐만 아니라 지능이 더 낮은 지적장애 아동 에 비해서도 틀린 믿음 과제를 통과하는 비율이 더 낮았다고 
Table 9. Correlation coefficient between subtasks of mind-reading ability and pragmatic language ability of children with typical development

\begin{tabular}{lccccccc}
\hline Category & SF & MA & AH & FP & DM & CV & CI \\
\hline SF & 1 & & & & & & \\
MA & -0.339 & 1 & & & & & \\
AH & 0.017 & 0.131 & 1 & & & & \\
FP & -0.247 & 0.193 & -0.135 & 1 & & & \\
DM & -0.128 & -0.079 & -0.100 & 0.011 & 1 & & 1 \\
CV & 0.058 & -0.032 & 0.129 & -0.062 & $0.647^{* *}$ & 1 & 0.173 \\
CI & 0.357 & -0.095 & 0.072 & 0.063 & 0.425 & 0.342 & 1 \\
NC & 0.411 & 0.337 & 0.127 & -0.040 & -0.083 & 0.182 & 0.173 \\
\hline
\end{tabular}

${ }^{* *} p<0.01$. SF: second-order false belief, MA: mind-reading in ambiguous situation, AH: apprehension of hidden meaning, FP: faux pas, DM: discourse management, CV: contextual variation, $\mathrm{CI}$ : communication intention, NC: nonverbal communication

하였다. 이는 마음에 대한 이해가 정상적인 사회적 상호작용과 의사소통에 요구되는 능력임을 보여줌과 동시에 사회적인 능 력, 즉 사회연령과도 밀접한 관련이 있음을 나타낸다. 또한 국 내에서는 Kim \& Ghim(2009)이 초등학교 6학년 아동을 또래 지위로 구분하여 얼굴 표정에서 마음을 읽는 과제로 마음이해 능력을 측정하여 비교한 결과, 또래관계에서 인기 있는 아동이 거부당하는 아동보다 마음이해능력이 더 높았음을 보고하였 다. 이러한 결과도 마음읽기능력이 사회적 능력과 연관이 있다 는 것을 주장하는 것이며, 두 연구 모두 마음읽기능력의 발달 을 생활연령 및 정신연령이 아닌 사회연령으로 보아야 한다는 본 연구의 주장을 뒷받침해 준다.

경도지적장애 청소년이 일반 아동보다 낮은 발달 수준을 나 타낸 근본적인 원인이 무엇인지 살펴보면 우선적으로 인지능력 의 결함에서 그 근거를 찾을 수 있을 것이다. 지적장애인의 인 지 특성으로는 특히 주의집중, 조직화, 기억, 일반화에서의 어려 움을 들 수 있다(Hwang \& Kim, 2010). 뿐만 아니라 경도지적 장애 청소년의 낮은 마음읽기능력의 발달에는 소극적인 의사 소통 태도나 명료화 요구하기 기능의 부족과 같은 그들이 가지 고 있는 고유한 언어적 특성으로 인한 영향도 배제할 수 없을 것이다. 따라서 임상 현장에서 지적장애 청소년의 마음이론을 중재하고자 할 때, 그들의 생활연령 및 정신연령이 아닌 사회연 령을 고려한 적절한 수준의 중재 모형을 개발하여 적용하는 것 이 그들의 마음이론 발달에 더욱 도움이 될 수 있을 것으로 사 료된다.

경도지적장애 청소년과 일반 아동 간 가장 크게 유의미한 수 행 차이가 나타난 하위과제는 모호한 상황에서의 마음읽기와 헛디딤 말이었다. 이는 초등학교 6학년 학생과 중학교 2학년 학 생을 대상으로 마음읽기능력을 살펴본 Choi \& Ghim(2008)의 연구와 일치된 결과를 보였다. 이러한 결과는 마음이론을 구성 하고 있는 여러 능력 간에 각각 다른 발달 순서를 보이기 때문 인 것으로 유추할 수 있다. 즉, 어린 아동이 바람이나 믿음보다 는 의도나 틀린 믿음을 비교적 나중에 이해하는 것과 같은 원
리로, 경도지적장애 청소년들 또한 이차순위 틀린 믿음을 이해 하고, 이후에 말의 숨은 의미나 모호한 상황에서의 마음읽기, 그리고 헛디딤 말을 이해하는 것으로 해석할 수 있다.

마음읽기능력의 하위과제별 수행 수준을 높은 순으로 살펴 본 결과 두 집단 모두 이차순위 틀린 믿음, 숨은 의미 파악, 헛 디딤 말, 모호한 상황에서의 마음읽기 순의 수행을 보였는데, 이는 경도지적장애 청소년의 마음읽기능력이 일반 아동에 비 해 지체되기는 하지만 특이한 패턴을 보이지 않는다는 것을 보 여주고 있다.

다음으로 경도지적장애 청소년의 화용언어능력을 구체적으 로 살펴보기 위해 일반 아동과 비교한 결과, 모든 화용언어능력 의 하위 영역에서 일반 아동에 비해 낮은 수행력을 나타냈다. 지 적장애 아동 및 청소년은 타인과 의사소통할 수 있는 언어능력 을 가지고 있음에도 불구하고, 화용적 측면에서 가장 큰 어려움 을 나타내며, 화용언어 발달에서 독특한 특성을 지니고 있거나 지체되는 특성을 보인다. 뿐만 아니라 Fujiki \& Brinton(2009)은 화용언어의 결함 일부가 언어구조 제약에 기인할 수 있는 아동 이 있는 반면에, 화용적 문제가 언어구조 결함에 기인하는 문 제를 넘어선 것으로 보이는 아동들도 있음을 논의하였으며, McCord \& Haynes(1988)는 의미론과 구문론에서 장애가 없 는 것으로 나타난 학습장애 학생들에게서도 일부 화용적 어려 움이 나타난다고 보고하였다. 사실상 화용론은 언어장애를 지 닌 아동 및 청소년의 구어에서 가장 심각한 결함이 있는 영역 일 것으로 추측된다. 그리고 이러한 발견들은 지적장애 청소년 의 화용언어기술의 평가와 그에 따른 적절한 중재 방안을 제시 하는 것에 대한 중요성을 더욱 강조하고 있다.

특히 화용언어능력의 하위과제 중에서 경도지적장애 청소년 과 일반 아동 간 가장 크게 수행 차이가 나타남과 동시에 경도 지적장애 청소년이 가장 저조한 수행력을 보인 영역은 상황에 따른 조절인 것으로 나타났다. 경도지적장애 청소년의 상황에 따른 조절에서의 어려움은 지적장애 아동이 다양한 상황 맥락에 서 적절하게 표현하는 능력에 결함을 나타낸다고 보고한 Paul \& 
Norbury(2012)의 연구 결과와 일치한다. 경도지적장애 아동은 상황 맥락 단서를 이용한 발화에서 언어학적인 형태를 바꾸는 것을 학습할 수는 있지만, 일반 아동과 비교하였을 때 수행력이 떨어지는 특성을 나타낸다(McLean \& McLean, 1999). 이와 같 이 상황에 따른 조절에서의 저조한 수행은 경도지적장애 청소 년의 추론능력과 마음읽기능력의 발달적 지체와 연관 지어 생 각해 볼 수 있다. 관련 연구로 경도지적장애 아동의 제한된 작 업 기억으로 인해 추론능력도 지체될 수 있거나(Yeo et al., 2001), 마음읽기능력의 결함이 화용언어능력에 부정적 영향을 미칠 수 있음이 보고되기도 하였다(Park, 2011).

이러한 연구 결과들을 근거로 경도지적장애 청소년은 추론 능력과 마음읽기능력의 발달이 지연되어 상황에 따른 조절에 서도 어려움을 가질 것으로 추측할 수 있으며, 이로 인해 상황 맥락과 대화 내용을 통합하고 추론하여 화자의 의도를 파악해 야 하는 의사소통 상황에서 어려움을 보일 것으로 예상된다. 따라서 이와 같은 결과를 토대로 경도지적장애 청소년에게는 화자의 의도를 이해하기 위한 추론능력과 상대방의 마음상태 를 잘 예측하기 위해 필요한 마음읽기능력, 그리고 의사소통 상 황에서 맥락을 적절히 이용할 수 있는 상황에 따른 조절능력과 같은 요소들을 함께 다루는 통합적 중재 접근이 요구된다는 것 을 알 수 있다.

마음읽기능력과 화용언어능력 간 연관성을 알아보기 위해 두 변인 간 상관관계를 살펴보았다. 여기에서는 마음읽기능력 과 화용언어능력의 각 변인 내에서 나타난 상관관계는 제외하 고, 두 변인 간에서 나타난 상관관계만 언급하고자 한다. 각 집 단별로 나누어 살펴보았을 때 경도지적장애 청소년 집단에서 는 헛디딤 말과 비언어적 의사소통 간에서만 유의미한 정적 상 관이 나타났으며, 일반 아동 집단에서는 상관이 나타나지 않았 다. 이를 통해 마음읽기능력과 화용언어능력 간 연관성이 경도 지적장애 청소년에게 더욱 강하게 작용함을 알 수 있으며, 이와 같은 결과는 경도지적장애 청소년의 사회적 의사소통능력과 마음읽기능력 간에 정적 상관이 있었음을 보고한 $\mathrm{Kim} \&$ $\mathrm{An}(2017)$ 의 연구 결과와도 일치한다. 의사소통이라는 큰 범주 안에 언어능력과 사회화, 상호작용 등을 담은 화용론적 측면 역시 자리하고 있으므로 경도지적장애 청소년의 삶의 질 향상 을 위해서는 그들의 여러 가지 언어적 특성을 고려한 의사소통 중재 프로그램이 다양화되고 확대되어야 할 것이며, 화용언어 중재 시 마음읽기능력 요소를 적절히 접목하여 지도한다면 더 욱 긍정적인 중재 효과를 얻을 수 있을 것으로 사료된다.

사회에 적응하면서 자립생활을 준비해야 하고, 의사소통 가 운데 자기결정능력을 키워야 하는 청소년기 및 초기 성인기의 지적장애인들에게는 교육해야 할 많은 과제들이 존재한다. 특히 마음읽기능력이나 화용언어능력이 지체되어 있을 경우, 의사소
통 상황에서 어려움을 겪는 것은 물론 학교생활, 직업생활 및 사회생활을 영위해 나감에 있어서도 어려움을 겪을 수 있다. 이 러한 관점들을 고려해 볼 때, 언어 영역에서의 화용론적 측면과 마음읽기능력은 지적장애 청소년에게 특히 시사하는 바가 크다.

본 연구는 경도지적장애 청소년을 대상으로 마음읽기능력과 화용언어능력 간 밀접한 관련성이 있음을 제시함으로써 후속 연구의 토대를 마련하였다는 데에 의의가 있으며, 마음읽기능 력과 화용언어능력에 대해 통합적 중재의 필요성을 제안하였 다는 점에서 의미가 있다. 이러한 점을 통해 경도지적장애 청소 년의 원만한 사회적, 직업적 관계 형성 및 유지를 위해서는 마 음읽기능력과 화용언어능력에 대한 적절한 평가 및 중재가 필 요하며, 이와 관련한 연구 역시 활발히 진행되어야 함을 시사 한다. 뿐만 아니라 마음읽기능력 및 화용언어능력은 구조적 환 경에서의 접근을 통해서는 향상되지 못하기 때문에 경도지적 장애 청소년의 긍정적 변화 촉진 및 일반화를 위해서는 상황 맥락에 적절하게 의사소통을 할 수 있도록 환경을 조성해 줄 필요성이 있을 것으로 사료된다. 더 나아가 본 연구의 결과가 경도지적장애 청소년의 마음읽기능력을 접목한 언어 및 의사 소통 관련 평가 도구 개발과 중재 수립에 유용한 지식 기반이 될 수 있기를 기대한다.

중심 단어 : 경도지적장애 청소년·마음읽기능력·화용언어능 력·마음이론.

\section{Ethical Statement}

This study was approved by the Institutional Review Board of Daegu University (IRB\#: 1040621-202009-HR-022).

\section{Acknowledgments}

N/A

\section{Declaration of Conflicting Interests \\ There are no conflict of interests.}

\section{Funding}

N/A

\section{Author Contributions}

J.C. designed and performed experiments, analyzed data, and wrote the paper; J.C. designed and performed experiments in the clinic; W.K. provided statistical analysis and critical revision. Also, the authors discussed the results together and implications and commented on the manuscript at each stage.

\section{ORCID iDs}

Jeongmin Cheon https://orcid.org/0000-0002-5696-5990

Whasoo Kim https://orcid.org/0000-0003-4787-4824

\section{REFERENCES}

Adams, C. (2002). Practitioner review: The assessment of language pragmatics. Journal of Child Psychology and Psychiatry, 43(8), 973-987. 
Adams, C. (2005). Social communication intervention for school-age children: Rationale and description. Seminars in Speech and Language, 26(3), 181-188.

American Psychiatric Association (2013). DSM-5 Diagnostic and Statistical Manual of Mental Disorders. (5th ed.). Washington, DC: American Psychiatric Publishing

Baron-Cohen, S. (1997). Mindblindness: An Essay on Autism and Theory of Mind. Cambridge, MA: MIT Press.

Baron-Cohen, S., Leslie, A. M., \& Frith, U. (1985). Does the autistic child have a "theory of mind"? Cognition, 21(1), 37-46.

Baron-Cohen, S., O’Riordan, M., Stone, V., Jones, R., \& Plaisted, K. (1999). Recognition of faux pas by normally developing children and children with Asperger syndrome or high-functioning autism. Journal of Autism and Developmental Disorders, 29(5), 407-418.

Bosacki, S. \& Astington, J. W. (1999). Theory of mind in preadolescence: Relations between social understanding and social competence. Social Development, 8(2), 237-255.

Cheon, J. M. \& Kim, W. S. (2017). Comparison of the quality of communication life between young adults and late middle age people with intellectual disabilities: Focusing on social communicative competence. Journal of Special Education and Rehabilitation Science, 56(4), 425-443.

Choi, H. O. \& Ghim, H. R. (2008). Understanding of mind and social skills in adolescents. Korean Psychological Journal of Culture and Social Issues, 14(1), 1-18.

Dunn, J., Brown, J., Slomkowski, C., Tesla, C., \& Youngblade, L. (1991). Young children's understanding of other people's feelings and beliefs: Individual differences and their antecedents. Child Development, 62(6), 1352-1366.

Eisenmajer, R. \& Prior, M. (1991). Cognitive linguistic correlations of 'theory of mind' ability in autistic children. British Journal of Developmental Psychology, 9(2), 351-364.

Fujiki, M. \& Brinton, B. (2009). Pragmatics and social communication in child language disorders. In Schwartz, R. Handbook of Child Language Disorders (pp. 406-423). New York, NY: Psychology Press.

Happé, F. G. E. (1993). Communicative competence and theory of mind in autism: A test of relevance theory. Cognition, 48(2), 101-119.

Hoff, E. (2005). Language Development. Belmont, CA: Wadsworth Cengage Learning.

Hwang, B. M. \& Kim, K. S. (2010). Speech-Language Therapy of Children with Intellectual Disabilities. Seoul: Hakjisa.

Hwang, S. T., Kim, J. H., Park, K. B., Choi, J. Y., \& Hong, S. H. (2012). Korean Wechsler Adult Intelligence Scale-IV (K-WAIS-IV). Seoul: Inpsyt.

Jenkins, J. M. \& Astington, J. W. (1996). Cognitive factors and family structure associated with theory of mind development in young children. Developmental Psychology, 32(1), 70-78.

Jeon, B. U. (1996). A study of the development of pragmatic competence by mentally retarded children. Journal of Special Education, 13(1), 117-148.

Kim, A. R. \& Ghim, H. R. (2009). The relations between children's peer status and mindreading. The Korean Journal of School Psychology, 6(2), 149-169.

Kim, H., Kim, Y. T., Kim, J. A., \& Song, S. (2018). Pragmatic language characteristics of children with mild intellectual disabilities using audio-visual discourse tasks (KOPLAC). Communication Sciences and Disorders, 23(2), 298-312.

Kim, K. E. (1991). A comparative study of presupposition ability between normal and mentally retarded children (Unpublished master's thesis). The Graduate School Ewha Womans University, Seoul.

Kim, S. J. (2002). Preschoolers' development of understanding of false beliefs: Relations with language competence (Unpublished master's thesis). Yonsei University Graduate Shool, Seoul.

Kim, W. S. \& An, S. Y. (2017). Relations of competence of social communication, mind of theory, and popularity among children with normal language ability and adolescent with mild intellectual disability. Journal of Intellectual Disabilities, 19(4), 229-248.

Kim, Y. T., Hong, G. H., Kim, K. H., Jang, H. S., \& Lee, J. Y. (2009). Receptive and Expressive Vocabulary Test (REVT). Seoul: Seoul Community Rehabilitation Center.

Kwak, K. J. \& Jang, S. M. (2019). Korean Wechsler Intelligence Scale for Children-V (K-WISC-V). Seoul: Inpsyt.

McCord, J. S. \& Haynes, W. O. (1988). Discourse errors in students with learning disabilities and their normally achieving peers: Molar versus molecular views. Journal of Learning Disabilities, 21(4), 237-243.

McLean, J. E. \& McLean, L. K. (1999). How Children Learn Language. San Diego, CA: Singular Publishing Group.

O'Connor, T. G. \& Hirsch, N. (1999). Intra-individual differences and relationship-specificity of mentalising in early adolescence. Social Development, 8(2), 256-274.

Oh, S. J., Lee, E. J., \& Kim, Y. T. (2012). Preliminary study on developing test items of children's pragmatic language checklist. Journal of SpeechLanguage and Hearing Disorders, 21(2), 111-135.

Owens, R. E. Jr. (2012). Language Development: An Introduction. (8th ed.). Boston, MA: Pearson Education.

Park, K. H. (2011). Comparison of the theory of mind and executive function between children with mental retardation and autistic children. Journal of Special Education for Curriculum and Instruction, 4(1), 21-38.

Paul, R. \& Norbury, C. F. (2012). Language Disorders from Infancy through Adolescence: Listening, Speaking, Reading, Writing, and Communicating. (4th ed.). St. Louis, MO: Elsevier.

Perner, J. \& Wimmer, H. (1985). "John thinks that Mary thinks that..." attribution of second-order beliefs by 5 - to 10-year-old children. Journal of Experimental Child Psychology, 39(3), 437-471.

Philofsky, A., Fidler, D. J., \& Hepburn, S. (2007). Pragmatic language profiles of school-age children with autism spectrum disorders and Williams syndrome. American Journal of Speech-Language Pathology, 16(4), 368-380

Premack, D. \& Woodruff, G. (1978). Does the chimpanzee have a theory of mind? Behavioral and Brain Sciences, 1(4), 515-526.

Prutting, C. A. \& Kittchner, D. M. (1987). A clinical appraisal of the pragmatic aspects of language. The Journal of Speech and Hearing Disorders, 52(2), 105-119.

Song, M. J. (2008). Developmental Psychology. Seoul: Hakjisa.

Wellman, H. M. (1990). The Child's Theory of Mind. Cambridge, MA: MIT Press.

Yeo, K. E., Kim, N. Y., Jung, Y. S., \& Lee, T. H. (2001). A comparison study on the capacity of working memory between the mentally retarded and underachievers. Journal of Intellectual Disabilities, 3, 1-23.

Yi, S. M., Ghim, H. R., \& Kim, A. R. (2007). Developmental changes in understanding second-order mental states. The Korean Journal of Developmental Psychology, 20(4), 1-16. 


\section{APPENDICES}

\section{Appendix 1. 마음읽기능력검사에 대한 전반적인 구성}

\begin{tabular}{|c|c|c|c|c|}
\hline 하위과제 & 목적 & 총점 & 채점 기준 & 문항 수 \\
\hline $\begin{array}{l}\text { 이차순위 } \\
\text { 틀린 믿음 }\end{array}$ & $\begin{array}{l}\text { 특정 사실을 직접 접하지 못해 틀린 믿음을 가진 } \\
\text { 사람에 대해 사실을 알고 있다고 틀린 믿음을 } \\
\text { 가진 주인공의 마음을 이해하는지 알아보고자 함 }\end{array}$ & 14점 & $\begin{array}{l}\text { - 0점: 이해하지 못한 경우 } \\
\text { - 1점: 질문에 대해 정확히 이해하고 } \\
\text { 답을 한 경우 }\end{array}$ & 3 \\
\hline $\begin{array}{l}\text { 모호한 } \\
\text { 상황에서의 } \\
\text { 마음읽기 }\end{array}$ & $\begin{array}{l}\text { 여러 가지 모호한 상황에 처한 주인공의 정서와 } \\
\text { 마음을 얼마나 잘 이해하고 해석하는지 } \\
\text { 알아보고자 함 }\end{array}$ & 38점 & $\begin{array}{l}\text { - 0점: 이해하지 못한 경우 } \\
\text { - 1점: 마음상태에 근거하여 생각과 } \\
\text { 기분을 해석하고 설명하는 경우 } \\
\text { - 2점: 마음상태에 근거하여 생각과 } \\
\text { 기분을 구체적으로 해석하고 설명하는 } \\
\text { 경우 }\end{array}$ & 4 \\
\hline 숨은 의미 파악 & $\begin{array}{l}\text { 말을 문자 그대로 해석하지 않고 숨은 의미를 } \\
\text { 파악하는지, 그리고 그에 따른 마음상태를 } \\
\text { 이해하는지 알아보고자 함 }\end{array}$ & 24점 & $\begin{array}{l}\text { - 0점: 이해하지 못한 경우 } \\
\text { - 1점: 말의 숨은 의미를 파악하거나 } \\
\text { 그에 따른 마음을 잘 이해한 경우 }\end{array}$ & 6 \\
\hline 헛디딤 말 & $\begin{array}{l}\text { 의도하지는 않았지만 사실을 정확하게 알지 못해 } \\
\text { 다른 사람의 기분을 상하게 하는 헛디딤 말로 } \\
\text { 인해 다른 사람의 기분을 상하게 한 것을 } \\
\text { 이해하고 있는지 알아보고자 함 }\end{array}$ & 12점 & $\begin{array}{l}\text { - 0점: 이해하지 못한 경우 } \\
\text { - 1점: 주인공이 알지 못하여 다른 } \\
\text { 사람의 기분을 상하게 하였다는 것을 } \\
\text { 알고 있는 경우 }\end{array}$ & 4 \\
\hline
\end{tabular}




\section{Appendix 2. 마음읽기능력 하위과제별 문항 예시}

\begin{tabular}{|c|c|c|}
\hline 하위과제 & & 문항 예시 \\
\hline \multirow[t]{5}{*}{ 이차순위 틀린 믿음 } & \multicolumn{2}{|c|}{$\begin{array}{l}\text { 엄마가 호진이의 생일선물로 자동차 장난감을 사왔어. 호진이가 엄마에게 생일선물이 뭐냐고 묻자, 엄마는 } \\
\text { 호진이를 놀라게 해주려고 네가 무서워하는 곤충백과를 샀다고 말했어. 그런데 잠시 후 호진이는 우연히 } \\
\text { 엄마 가방에 자동차 장난감이 있는 것을 봤어. 호진이는 “엄마가 자동차 장난감을 샀네!"라고 말하며 } \\
\text { 좋아했어. }\end{array}$} \\
\hline & 질문 1 & 엄마는 호진이가 자동차 장난감을 봤다고 생각할까? \\
\hline & 질문 2 & 호진이는 생일선물로 무엇을 받을 것이라고 생각할까? \\
\hline & 질문 3 & 엄마는 호진이가 생일선물로 자동차 장난감을 받게 될 것이라고 생각한다는 것을 알까? \\
\hline & 질문 4 & $\begin{array}{l}\text { 아빠가 엄마에게 “호진이는 당신이 어떤 선물을 샀다고 생각하고 있어?”라고 물으면 엄마는 } \\
\text { 뭐라고 대답할까? }\end{array}$ \\
\hline
\end{tabular}

바로 이때, 엄마가 지나가다가 호진이가 자신의 가방에 들어있는 자동차 장난감을 만지면서 "엄마가 자동차 장난감을 샀네!”라고 말하며 좋아하는 모습을 봤어. 엄마는 호진이에게 들키지 않게 살짝 부억으로 가서 식사 준비를 하고 있어. 잠시 후, 호진이가 엄마에게 와서 "엄마, 정말 내 생일선물로 내가 싫어하는 곤충백과 샀어?" 하고 물었어. 그러자 엄마는 "내가 아까도 곤충백과 샀다고 그랬잖아. 너는 씩씩해질 필요가 있어. 그래서 씩씩해지라고 곤충백과 샀어."라고 말했어.

질문 5 엄마는 호진이를 속이고 있는 거니? 아니면 장난치고 있는 거니?

모호한 상황에서의 마음읽기
수정이와 예지가 운동장 벤치에 앉아 있어. 그때 수정이가 아무 말 없이 예지에게 고갯짓을 하고는 운동장 저쪽에서 그네를 타고 있는 어떤 여자아이를 봤어. 그리고 수정이는 다시 예지에게 눈을 맞추고는 씩 웃었어. 예지도 고개를 끄덕였어. 잠시 후, 수정이와 예지는 그네를 타고 있는 여자아이 쪽으로 갔어. 그 여자아이도 수정이와 예지가 자기를 향해 걸어오고 있는 것을 봤어. 그네를 타고 있는 여자아이는 수정이와 예지가 서로 고갯짓을 하고 웃는 것도 봤어. 이 둘은 그네를 타고 있는 여자아이와 같은 반이지만, 서로 말을 해 본 적은 없었어. 그래서 그네 타는 여자아이는 수정이와 예지가 왜 자기 쪽으로 오나 싶었어.

\begin{tabular}{l|l} 
질문 1 & 그네 타는 여자아이는 수정이와 예지가 서로 끄덕이고 웃는 것을 봤니?
\end{tabular}

질문 2 왜 수정이는 그네 타는 여자아이를 잠깐 본 후에 예지에게 씩 웃었을까?

질문 3 왜 예지가 고개를 끄덕였을까?

질문 4 왜 수정이와 예지는 그네 타고 있는 여자아이 쪽으로 갔을까?

질문 5 그네 타는 여자아이는 수정이와 예지가 왜 자기를 향해 온다고 생각할까?

질문 6 그네 타는 여자아이는 어떤 기분일 것 같니?

\begin{tabular}{l|l}
\hline 숨은 의미 파악 & 은주가 학교에 갔더니 친한 친구인 혜수가 새 목도리를 하고 왔어. 그 목도리는 붕대같이 생긴 게 아주
\end{tabular} 우스꽝스러워 보였어. 혜수가 "이 목도리 새로 샀어. 어때? 예쁘지?" 하고 물었어. 은주는 "응. 예쁘다. 멋지네. 좋겠다."라고 말했어.

질문 1 목도리가 정말 예쁘니?

질문 2 은주는 왜 “응. 예쁘다. 멋지네. 좋겠다."라고 말했을까?

질문 3 은주의 말을 듣고 혜수는 어떤 생각을 할까?

질문 4 혜수의 생각은 맞는 거니?

\begin{tabular}{l|l}
\hline 헛디딤 말 & 철수 엄마는 선생님인데 이번에 새로운 학교로 왔어. 5학년 4반 선생님이야. 철수도 이 학교로 전학을
\end{tabular} 왔어. 어느 날 짝꿍이 "야, 너 5학년 4반 선생님 알아? 그 여자 정말 웃기더라. 혼자서 똑똑한 척하고 애들 엄청 무시해."라고 말했어. 철수는 "그래? 난 잘 모르겠는데...”라고 말했어.

질문 1 철수 짝꿍은 왜 5학년 4반 선생님에 대해 안 좋게 애기했을까?

질문 2 철수 짝꿍은 5 학년 4반 선생님이 철수 엄마인 것을 알았을까?

(질문 2에서 "몰라요."한 경우) 만약 5 학년 4반 선생님이 철수 엄마인 것을 짝꿍이 알고 있었다

질문 3
면, 뭐라고 말했을까?

(질문 2에서 “알아요."한 경우) 만약 5학년 4반 선생님이 철수 엄마인 것을 짝꿍이 모르고 있었 다면, 뮈라고 말했을까? 
ASR

A Relationship between Theory of Mind and Pragmatic Language

\section{Appendix 3. 화용언어능력검사에 대한 전반적인 구성}

\begin{tabular}{|c|c|c|c|}
\hline 하위과제 & 개념 & 문항 수 & 문항 예 \\
\hline 담화관리 & $\begin{array}{l}\text { • 주제 관리 } \\
\text { - 주제 개시 } \\
\text { - 주제 유지 } \\
\text { - 주제 전환 } \\
\text { - 의사소통 단절 수정 } \\
\text { - 대화 차례 주고받기 }\end{array}$ & 11 & $\begin{array}{l}\text { 한 가지 주제로 } 5 \text { 회 이상 대화를 주고받을 수 있다. } \\
\text { 먼저 대화를 시작하는 횟수가 다른 또래들과 비슷하다. }\end{array}$ \\
\hline 상황에 따른 조절 & $\begin{array}{l}\text { · 전제능력 } \\
\text { • 언어 사용역 } \\
\text { • 참조기술 }\end{array}$ & 13 & $\begin{array}{l}\text { 듣는 사람에 따라 목소리나 내용을 조정할 수 있다. } \\
\text { 한 가지 지시어의 과도한 사용 없이 지시어를 정확하게 사용할 수 } \\
\text { 있다. }\end{array}$ \\
\hline 의사소통 의도 & $\begin{array}{l}\text { - 의사소통 기능의 다양성 } \\
\text { - 의사소통 기능의 성숙도 } \\
\text { - 간접적 표현 }\end{array}$ & 13 & $\begin{array}{l}\text { 자기가 잘하는 일에 대해 다른 사람에게 시범을 보이거나 가르칠 } \\
\text { 수 있다. } \\
\text { 화해하거나 조정할 일이 있을 때 적절하게 언어적으로 협상할 수 } \\
\text { 있다. }\end{array}$ \\
\hline 비언어적 의사소통 & $\begin{array}{l}\cdot \text { 눈 맞춤 } \\
\text { · 표정 } \\
\text { · 제스처 } \\
\text { - 신체적 접촉 및 거리 }\end{array}$ & 10 & $\begin{array}{l}\text { 대화 시 상대방을 적절히 쳐다볼 수 있다. } \\
\text { 다른 사람의 표정을 보고 화나거나 언짢음 등의 기분을 잘 파악할 } \\
\text { 수 있다. }\end{array}$ \\
\hline
\end{tabular}

